\title{
Assessment of Environmental Knowledge and Attitude of Secondary Level Students of Tangail, Bangladesh
}

\author{
Negar Sultana, Md. Shahadat Hossen*, Rehana Khatun \\ Department of Environmental Science \\ Bangladesh Agricultural University, Mymensingh, Bangladesh \\ *Corresponding Author: mshossen@bau.edu.bd
}

\begin{abstract}
A study was conducted to assess the environmental knowledge and attitude of secondary level students in Tangail sadar upazila of Tangail district during January to April, 2015. Three hundred students of class nine and ten grade were randomly selected from 10 different private and government schools. The data were collected using questionnaire survey method. Results of the study revealed that the level of environmental knowledge of the secondary level student was high. Their average knowledge level was 15.83 ( \pm 3.07 ) out of 20. They had positive attitude towards environment. The order of environmental knowledge and environmental attitude of the students group was Science> Commerce> Arts and Arts>Commerce>Science, respectively. Government school students had high attitude level than private schools. In case of gender of students there were no significant differences in environmental knowledge and attitude. Urban students had higher knowledge level and rural students had higher attitude level. Higher education of parents influenced the environmental awareness of students. About fifty percent students thought television was one of the most important sources of environmental awareness. The study concluded that a high level of understanding and positive attitude of students might be achieved from the families of respondents, teachers, media, private reading and school curriculums regarding the environment that increase the environmental view among students as well as in the society.
\end{abstract}

Keywords: Secondary school, environmental knowledge, attitude, television, gender.

\section{INTRODUCTION}

Environment is now a mostly discussed issue in our daily life. From the smallest microorganisms to the largest animals, all life on Earth are closely related to their environment. Humans are part of nature depended on healthy ecosystems for their survival. In the same time, human activities negatively influences the healthy environment for present and future generation as a consequence of environmental pollution, climate change and disaster. Development of science and rising environmental problems increased environmental awareness among the public over the last few decades (Decamps, 2000; Thapa, 2001).

Bangladesh is facing tremendous environmental problems for its overpopulation and unplanned industrial growth. Flood, river pollution, river erosion, deforestation, food contamination and adulteration etc are the most common environmental issues facing the whole country. Previous study found that most of the citizens of many developing nations were highly concerned about the state of the environment (Dunlap et al., 1993). Environmental education is one of the most effective strategies for increasing public environmental perception, knowledge, and attitude. Since the schools teach young generations who are expected to be the future leaders in many different areas of the society and who will be the decision-makers, the role of the schools in the environmental training of the public is huge. If schools education create positive attitudes of students towards environment they would take an active role in conserving the environment and its resources and hence preserve them for the future generation.

In Bangladesh, environmental education is introduced at the primary level in Grade III where two units deal with environmental education named "Introduction to Environment: Science" and "Introduction to Environment: Social Science" (NCTB, 2003). At the secondary level, environment related themes are emphasized in the General Science unit, which is studied by students from the 
Humanities, and Business Studies group, consisting of almost $75 \%$ of the total secondary students (BANBEIS, 2006). The secondary level is very important in Bangladesh context, since this is the terminal education for one-third of the total number of students (BANBEIS, 2006). Although many research studies found positive attitude of people towards the environment (Bulent et al., 2009) but there exists a gap between the conceptual knowledge of environment and the motivation to participate in environmental conservation. Positive attitude towards environment includes the protection of environment and also individuals positive opinions, feelings, and behaviors towards functions of living creatures in their lives (Turkum, 1998). The main purpose of education for environment is not only to give information about the environment but also to gain attitudes and behaviors to develop and protect the environment and problem solving methods. Students positive attitudes towards the environment correlated with talking and discussion about the environment at home, watching nature in TV and reading about the environment (Eagles and Demare, 1999). Tikka et al. (2000) found that students involving in nature-related activities had higher level of environmental attitude.

Environmental education should be a lifelong process and environmental awareness among the students is highly influenced by their background knowledge, attitude and sensitivity towards the environment. The purposes of this research is to investigate the environmental knowledge and attitude of secondary level students and also find out whether there is a difference in environmental knowledge and attitude according to gender, school type, school location and parents education of students.

\section{Materials AND Methods}

The present study was conducted in Tangail sadar upazila, Tangail district, the central region of Bangladesh. The study was conducted by sampling 300 students from class nine and ten of five governmental and five private schools covering both urban and rural areas. The target students of each school were informed by their teacher in-charge that they would participate in an educational research program. Data were collected through pre-tested questionnaire. The study was conducted for the period of 12 weeks from January to April, 2015. In the scope of this research a six-step questionnaire was prepared. Part $A$ consists of general information about class, group, name of school, age, gender, family background, parents occupation, parents educational qualification; Part $B$ consists of environmental knowledge; Part $C$ consists of sources of environmental awareness; Part D consists of level of concern in different environmental issues; Part $E$ consists of environmental attitude and understanding and Part $F$ consists of different opinion on environmental related issues. The entire questionnaire was constructed in English and finally translated to native language Bengali.

In order to determine environmental knowledge, there was 20 questions related to environmental issues and problems where possible score ranged from 0-20. In addition there were 20 questions related to positive and negative attitude towards environment to determine their attitude level where possible score ranged from 0-20. The level of environmental knowledge and attitude of the respondents was categorized into three groups (low <10; medium 10-14 and high>14 out of 20). Data was analyzed by using SPSS and Microsoft excel. Descriptive statistic was used to describe the characteristic of sample and proportion of answer by respondents for each item. student T-test was also done to find out the significant level of some variables.

\section{RESULTS AND DISCUSSION}

\section{Environmental knowledge and attitude}

The analysis demonstrated that the students in this study had a high level of environmental knowledge. $79 \%$ of the student had high level of environmental knowledge whereas only $1 \%$ had low level of environmental knowledge (Table 1). This high level of knowledge may be due to media and influenced by their education. The average level of environmental knowledge was 15.83(out of 20.0). Study conducted in Malaysia showed that more than $80 \%$ of all students had the high level of attitude and knowledge (Reja et at., 2003). The average level of environmental attitude was 16.33 (out of 20.0). Among the participants, $75 \%$ had higher level of environmental attitude and $4 \%$ had low level of environmental attitude (Table 1). In both cases, only $20 \%$ had medium level of environmental knowledge and attitude. Bradley et al. (1999) found that students having higher knowledge scores had more favorable environmental attitudes. 
Assessment of Environmental Knowledge and Attitude of Secondary Level Students of Tangail, Bangladesh

Table 1. Level of environmental knowledge and attitude of students

\begin{tabular}{|c|c|c|c|c|c|}
\hline $\begin{array}{l}\text { Level of } \\
\text { environmental } \\
\text { knowledge }\end{array}$ & $\begin{array}{c}\text { No. of } \\
\text { respondents }\end{array}$ & Percentage & $\begin{array}{l}\text { Level of } \\
\text { environmental } \\
\text { Attitude }\end{array}$ & $\begin{array}{c}\text { No. of } \\
\text { respondents }\end{array}$ & Percentage \\
\hline Low & 3 & 1 & Low & 12 & 4 \\
\hline Medium & 61 & 20 & Medium & 64 & 21 \\
\hline High & 236 & 79 & High & 224 & 75 \\
\hline Total & 300 & 100 & Total & 300 & 100 \\
\hline
\end{tabular}

\section{Comparison of environmental knowledge and attitude level}

Figure 1 (a) shows the average level of environmental knowledge and attitude based on science, commerce and arts group, where bar indicates the standard deviation. It is found that there was a difference in average level of environmental knowledge and attitude, where science group students had higher environmental knowledge and arts students had lower environmental knowledge. There was statistical significant difference in environmental knowledge level among different groups' students $(\mathrm{F}=15.05$, $\mathrm{p}$-value $=5.91 \mathrm{e}-07)$. Many environmental problems and their solutions are science related where students actively engage through both theoretically and practically. In case of environmental attitude level, reverse condition found where arts students had higher environmental attitude and science had lower. There was statistical significant difference in environmental attitude level among different groups' students $(\mathrm{F}=12.23$, p-value $=7.82 \mathrm{e}-06)$. Mishra (2012) found that the science students knowledge were significantly higher than arts students of govt. schools and science students were more aware about environmental problems in comparison to arts students.

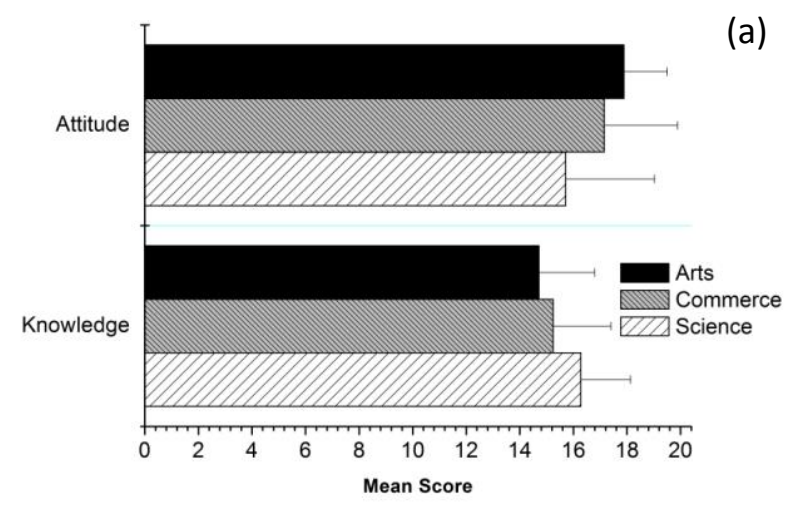

(b)
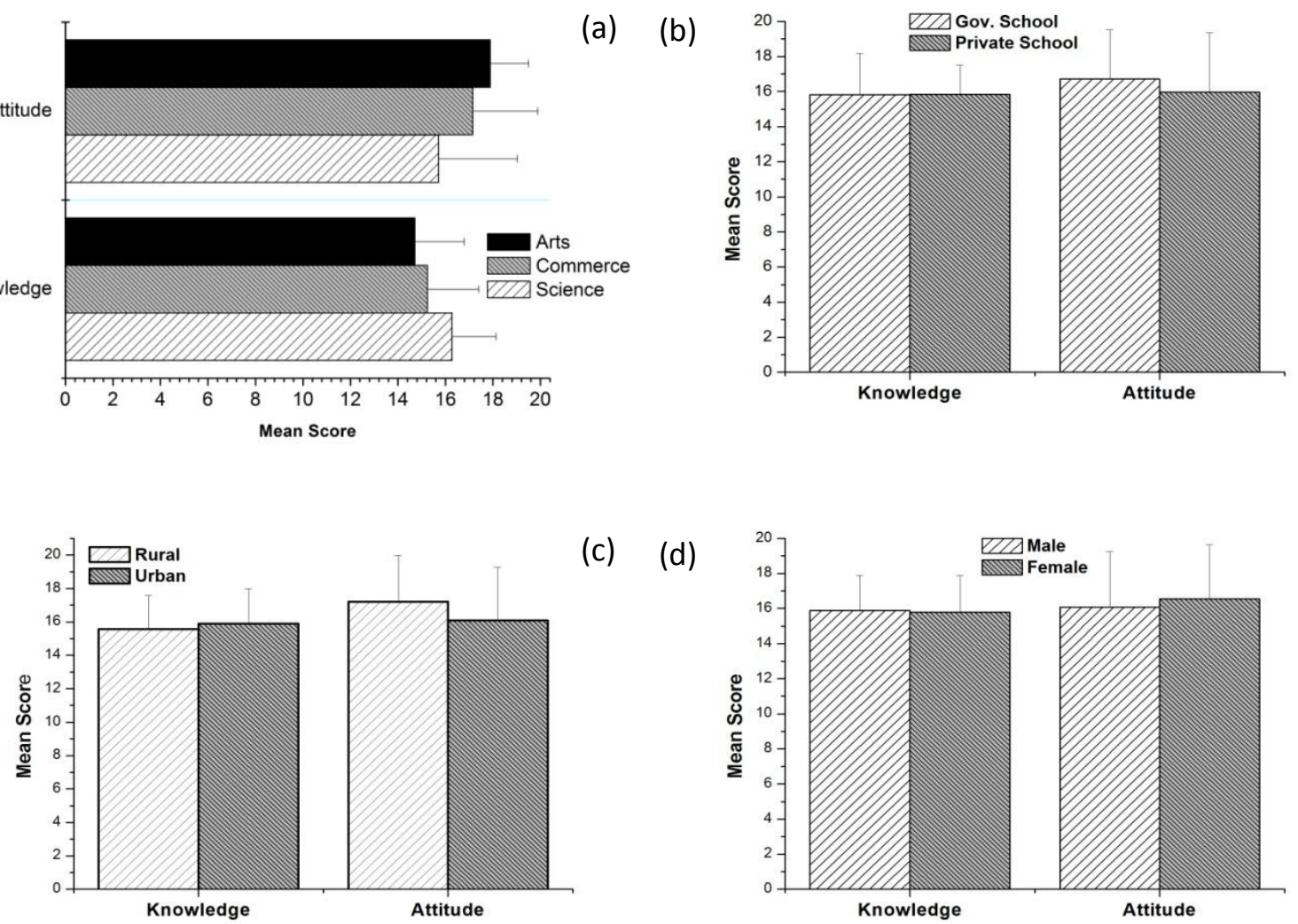

(c) (d)

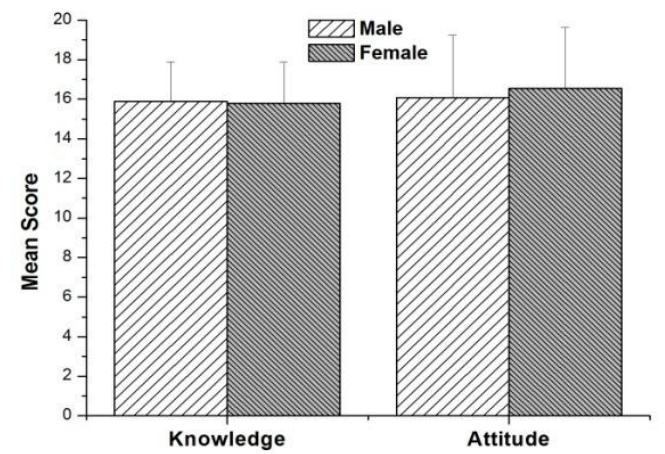

Figure 1. Comparison of environmental knowledge and attitude level of secondary school students based on a) study group; b) school type; c) school location and d) gender

From figure 1(b), it is found that there was small difference in environmental attitude level between government and private school where government school students had higher environmental attitude than private school students. But no difference was found in knowledge level between two types of school. Statistically there was no significant difference on the average level of environmental knowledge $(\mathrm{t}=-0.1689, \mathrm{df}=298, \mathrm{p}$-value $=0.866)$ but significant difference observed on attitude $(\mathrm{t}=$ 
2.1536, $\mathrm{df}=298, \mathrm{p}$-value $=0.03207)$ of government schools and private schools students. Poonam (2013) found significant difference between government and private secondary school students on environmental awareness in Punjab, India.

There was no significant difference between rural and urban students on the average level of environmental knowledge $(\mathrm{t}=1.1756, \mathrm{df}=298, \mathrm{p}$-value $=0.2407)$ where the average environmental knowledge of urban and rural school students were 15.9 and 15.6, respectively [Figure 1(c)]. However students living in rural areas had better environmental attitude than urban living students and have significant variation on environmental attitude $(-2.5464, \mathrm{df}=298, \mathrm{p}$-value $=0.01139)$. Environmental knowledge of urban students at secondary level were better than the rural students in India (Behera and Samal, 2015).

According to gender no difference was observed in environmental knowledge level but small difference was found in environmental attitude level between male and female students [Figure 1(d)]. There was no significant different between male and female students on the average level of environmental knowledge $(\mathrm{t}=0.3832, \mathrm{df}=298$, $\mathrm{p}$-value $=0.7019)$ and attitude $(\mathrm{t}=-1.3347, \mathrm{df}=298$, p-value $=0.183)$. Behera and Samal $(2015)$ also reported that there was no significant difference between boys and girls in relation to their environmental knowledge in West Bengal, India.

\section{Comparison of environmental knowledge and attitude level based on parental education}

Generally it is thought that parents having higher education make positive contributions to children environmental knowledge and attitude. It was found that environmental knowledge and attitude levels of students whose parents education status was Bachelor or above was higher than those of others students (Table 2). There was no statistically significant difference between environmental attitude scores of secondary students in terms of parents educational status but difference observed in knowledge level and parents educational status. It is also found that in environmental knowledge and attitude level student father's education status contribute more than mother's. Makki et al. (2003) found that participants with "more educated" fathers had significantly higher environmental knowledge scores, while there was no significant relationship between the mother's educational level and the participants' environmental knowledge scores in the same study. Tayci and Uysal (2012) reported that there was no significant relationship between the parent's educational status and the $8^{\text {th }}$ grade students environmental knowledge and attitude in Turkey. The study by Gambro and Switzky (1999), noticed that the level of formal education a student's parent received was significantly related to the student's level of knowledge concerning environmental issues.

Table 2. Comparison of environmental knowledge and attitude level based on parental educational level

\begin{tabular}{|l|l|l|l|l|l|l|l|l|}
\hline & $\begin{array}{l}\text { Father } \\
\text { education level }\end{array}$ & $\mathrm{N}$ & Mean & $\begin{array}{l}\text { Std } \\
\text { deviation }\end{array}$ & $\begin{array}{l}\text { Mother } \\
\text { education level }\end{array}$ & N & Mean & $\begin{array}{l}\text { Std } \\
\text { deviation }\end{array}$ \\
\hline \multirow{5}{*}{ Knowledge } & Below SSC & 36 & 14.83 & 2.19 & Below SSC & 60 & 15.32 & 2.06 \\
\cline { 2 - 9 } & SSC to HSC & 99 & 15.58 & 1.77 & SSC to HSC & 139 & 15.76 & 1.89 \\
\cline { 2 - 9 } Attitude & $\begin{array}{l}\text { Bechelor or } \\
\text { above }\end{array}$ & 167 & 16.21 & 2.07 & $\begin{array}{l}\text { Bechelor or } \\
\text { above }\end{array}$ & 99 & 16.19 & 2.16 \\
\cline { 2 - 9 } & Below SSC & 36 & 17.69 & 2.18 & Below SSC & 60 & 16.88 & 2.92 \\
\cline { 2 - 9 } & $\begin{array}{l}\text { SSC to HSC } \\
\text { Bechelor or } \\
\text { above }\end{array}$ & 169 & 16.42 & 3.05 & SSC to HSC & 139 & 16.24 & 3.26 \\
\hline
\end{tabular}

\section{Sources of environmental awareness}

According to Figure 2, majority of the respondents (49.2\%) said that television is the source of environmental awareness whereas $14.9 \%$ told about radio, $10.9 \%$ said about from elder, $11.3 \%$ mentioned to course curriculum and $13.7 \%$ claim NGO. Number of channels of Television and FM radio have risen a lot in last decade in Bangladesh. Television coverage of environmental problems has increased dramatically in last few decades. Newspaper and radio coverage also rise significantly. It is possible to learn about environmental problems and their solution without learning much about environmental concept in subject matters. According to McKibben (1992) television is the primary source of environmental information. Pawlowski (1996) studied the perception of environmental problems by young people in Poland where he found that the main source of environmental information for participating students were TV (television) (70\% at TU and 53.5\% at UMCS). Said et al. (2007) also found same results for secondary schools students in Malaysia. 


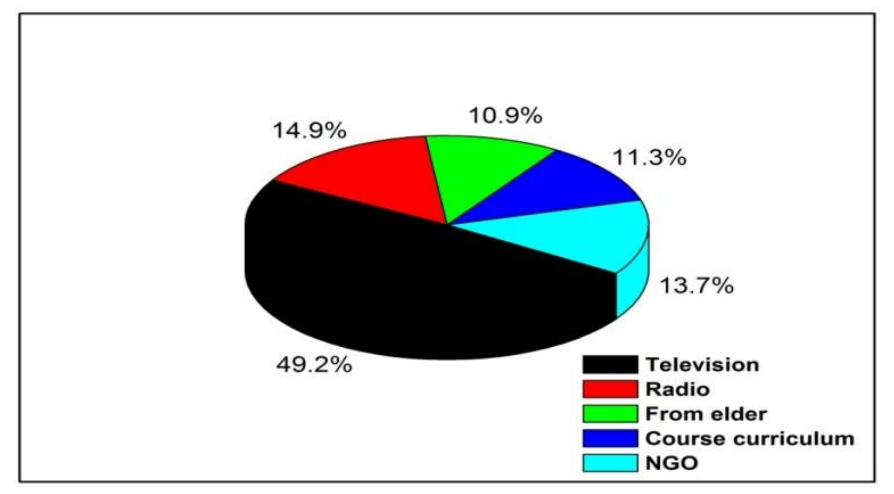

Figure 2. Sources of environmental awareness of the respondents

\section{CONClusion}

The results of the study indicated that secondary (grade 9 and 10) students of Tangail had higher level of environmental knowledge and attitude towards environmental issues. Similar environmental knowledge was observed regarding gender, school types, and school location but difference found in study group and environmental attitude level. Environmental sustainability will depend on our future actions which will be regulated and recommended by present young generation. Therefore, students environmental knowledge and attitude is an important issues for our healthy ecosystem. We need to think about curriculum content and structure, teaching methods, and development of suitable resources regarding environmental issues. Teachers need to use variety of innovative teaching strategies and student should be encouraged to take positive actions in their daily life. Moreover electronic media and NGOs should conduct some educational program on environmental issues to aware everyone. All students should take part in formal and informal education classes to promote their knowledge, understanding and awareness on environmental issue.

\section{REFERENCES}

Bangladesh Bureau of Educational Information and Statistics [BANBEIS] (2006): Output statistics. Retrieved 30 October, 2008, from BANBEIS, Government of Bangladesh: http://www.banbeis.gov.bd/db_bb/out_sta.htm.

Behera, J., and Samal R. M. ( 2015). Environmental Knowledge of Secondary School Students: A Topographical Analysis. International Journal of Social Science and Humanities Research Vol. 3 , Issue 2, pp 252-261.

Bradley, J. C., Waliczek, T. M., \& Zajicek, J. M. (1999). Relationship between environmental knowledge and environmental attitude of high school students. Journal of Environmental Education, 3(30), 17-21.

Bulent, C., Pinar C., Ceren,T., Jale, C. \& Teoman, K. (2009). Turkish Students' Views on Environmental Challenges with respect to Gender: An Analysis of ROSE Data. Science Education International, 20(1/2), 69-78.

Decamps H (2000). Demanding more of Landscape Research (and researches) Landscape and Urban Planning. Environmental Pollution 47 105-109.

Dunlap, Riley E., George H. Gallup, Jr., and Alec M. Gallup. (1993). "Of Global Concern: Results of the Health of the Planet Survey." Environment 35: 7-15, 33-39.

Eagles, P. and Demare, R. (1999). Factors influencing children's environmental attitudes. Journal of Environmental Education, 30, 33-37.

Gambro, J. S., \& Switzky, H. N. (1999). Variables associated with American high school students knowledge of environmental issues related to energy and pollution. Journal of Environmental Education, 2(30), 15-22.

Makki, M. H., Abd-El-Khalick, F., \& Boujaoude, S. (2003). Lebanese secondary school students' environmental knowledge and attitudes. Environmental Education Research, 1(9), 21-33.

McKibben, W. (1992). The age of missing information. New York: Random House. 
Mishra, S. K. (2012). Environmental awareness among senior secondary students of Maheshwar and Mandleshwar, Dist.- Khargone (M.P.). International Journal of Scientific and Research Publications, Volume 2, Issue 11.p 1-3.

National Curriculum and Textbook Board [NCTB] 1996: Curriculum and syllabus: Junior secondary level (grades VI-VIII) [in Bengali]. Dhaka: Ministry of Education, Government of Bangladesh.

Pawlowski, A. (1996). Perception of environmental problems by young people in Poland. Environmental Education Research, 3(2), 279-285.

Poonam. (2013). A Comparative Study of Environmental Awareness among Government and Private Secondary School Students. International Journal of Education and Information Studies. Volume 3, Number 2 pp. 39-41

Reja, U., K.L. Manfreda, V. Hlebec and V. Vehovar, (2003). Open-ended vs. Close-ended Questions in Web Developments in Applied Statistics, Metodološkizvezki, 19, Ljubljana: FDV.

Said, A. M., Yahaya, N., \& Ahmadun, F. (2007). Environmental comprehension and participation of Malaysian secondary school students. Environmental Education Research, 1(13), 17-31.

Tayci, F. and Uysal, F. (2012). A study for determining the elementary school students' environmental knowledge and environmental attitude level. Procedia - Social and Behavioral Sciences, 46, $5718-5722$.

Thapa, B. (2001). Environmental concern: a comparative analysis between students in recreation and park management and other departments. Environmental Education Research 7, 39-53.

Tikka, P.M., Kuitunen, M.T \& Tynys, S.M. (2000). Effects of educational background on students' attitudes, activity levels, and knowledge concerning the environment. The Journal of Environmental Education, 31(3), 12-19.

Türküm A.S., (1998), Environmental Problems And Environmental Consciousness In Contemporary Society (Ed. Prof. Dr. Gurhan Can), Anadolu University Publications, Eskişehir. 